\title{
Electron-Induced Radiolysis of Astrochemically Relevant Ammonia Ices
}

\author{
Katherine E. Shulenberger, Jane L. Zhu, Katherine Tran, Sebiha Abdullahi, Carina Belvin, Julia \\ Lukens, Zoe Peeler, Ella Mullikin, Helen M. Cumberbatch, Jean Huang, Kathleen Regovich, \\ Alice Zhou, Lauren Heller, Milica Markovic, Leslie Gates, Christina Buffo, Rhoda Tano-Menka, \\ and Christopher R. Arumainayagam ${ }^{\mathrm{a}}$ \\ Department of Chemistry, Wellesley College, Wellesley, MA 02481 \\ Esther Böhler, Petra Swiderek, \\ Institute of Applied and Physical Chemistry, University of Bremen, D-28334 Bremen, Germany \\ Sasan Esmaili, Andrew D. Bass, Michael Huels, and Léon Sanche \\ Department of Nuclear Medicine and Radiobiology, University of Sherbrooke, Sherbrooke, QC, Canada
}

\begin{abstract}
$\underline{\text { Abstract }}$
We elucidate mechanisms of electron-induced radiolysis in cosmic (interstellar, planetary, and cometary) ice analogs of ammonia $\left(\mathrm{NH}_{3}\right)$, likely the most abundant nitrogen-containing compound in the interstellar medium (ISM). Astrochemical processes were simulated under ultrahigh vacuum conditions by high-energy $(1 \mathrm{keV})$ and low-energy $(7 \mathrm{eV})$ electron-irradiation of nanoscale thin films of ammonia deposited on cryogenically cooled metal substrates.

Irradiated films were analyzed by temperature-programmed desorption (TPD). Experiments with ammonia isotopologues provide convincing evidence for the electron-induced formation of hydrazine $\left(\mathrm{N}_{2} \mathrm{H}_{4}\right)$ and diazene $\left(\mathrm{N}_{2} \mathrm{H}_{2}\right)$ from condensed $\mathrm{NH}_{3}$. To understand the dynamics of ammonia radiolysis, the dependence of hydrazine and diazene yields on incident electron energy, electron flux, electron fluence, film thickness, and ice temperature were investigated. Radiolysis yield measurements versus (1) irradiation time and (2) film thickness are semi-quantitatively consistent with a reaction mechanism that involves a bimolecular step for the formation of hydrazine and diazene from the dimerization of amidogen $\left(\mathrm{NH}_{2}\right)$ and imine $(\mathrm{NH})$ radicals, respectively. The apparent decrease in radiolysis yield of hydrazine and diazene with decreasing electron flux at constant fluence may be due to the competing desorption of these radicals at 90 $\mathrm{K}$ under low incident electron flux conditions. The production of hydrazine at electron energies as low as $7 \mathrm{eV}$ and an ice temperature of $22 \mathrm{~K}$ is consistent with condensed phase radiolysis being mediated by low-energy secondary electrons produced by the interaction of high-energy radiation with matter. These results provide a basis from which we can begin to understand the mechanisms by which ammonia can form more complex species in cosmic ices.
\end{abstract}

Key words: radiation chemistry, interstellar ice, cosmic rays, photochemistry, $\mathrm{NH}_{2}$ radicals, $\mathrm{NH}$ radicals

${ }^{a}$ Corresponding Author: Telephone 781-283-3326; FAX: 781-283-3642; Email: carumain@wellesley.edu 


\section{$1 \quad$ Introduction}

\subsection{Astrochemical relevance and motivation for investigating ammonia}

Ammonia $\left(\mathrm{NH}_{3}\right)$ is of astrochemical interest due to its presence in diverse extraterrestrial environments. For example, the microwave sounding measurements made in August 2016 by the Juno spacecraft provided convincing evidence for an ammonia-rich plume in the atmosphere of Jupiter. ${ }^{1}$ Significant amounts of ammonia have been detected in the atmospheres of Saturn, ${ }^{2}$ Uranus, ${ }^{3}$ and Neptune, ${ }^{4}$ as well as on the surface of Saturn's moon, Enceladus. ${ }^{5}$ Additionally, cometary ices in the Halley, Borrelly, Hartley-Good, and Thiele comets exhibit substantial ammonia abundances $(>10 \%)$ relative to water. ${ }^{6}$ Studies of interstellar ice composition in protostellar regions indicate that with the possible exception of molecular nitrogen, that ammonia is the most prevalent nitrogen-containing compound in interstellar ices, with an abundance of 1 $10 \%$ relative to water. ${ }^{7}$ Gas phase $\mathrm{NH}_{2}$ radicals discovered in the interstellar medium ${ }^{8}$ may result from radiation processing of ammonia ices or from ground state $\mathrm{N}$ atoms reacting with ammonia in the solid phase. ${ }^{9}$ Moreover, the relatively high abundance of ammonia in starforming regions and elsewhere suggests that it may be a precursor for $\mathrm{N}$-containing prebiotic molecules. The discovery in 2016 of glycine in the coma around Comet 67P/ChuryumovGerasimenko by Rosetta's ROSINA spectrometer is significant since comets are thought to have preserved icy grains initially present in the interstellar medium prior to star formation. ${ }^{10}$ Cyanomethanimine $\left(\mathrm{NC}_{2} \mathrm{HNH}\right)$, a $\mathrm{C}-\mathrm{N}$ bond containing prebiotic molecule recently discovered in an interstellar gas cloud $(\mathrm{Sgr} B 2(\mathrm{~N})),{ }^{11}$ is of particular interest because experimental and theoretical studies suggest that it cannot be formed in the gas phase. ${ }^{12}$ Therefore, understanding the energetic processing of ammonia ices may provide insights into how complex prebiotic 
species form in condensed phase environments within the interstellar medium. While our recent work characterizes the photochemistry of condensed ammonia, ${ }^{13}$ this work focuses on the other major form of energetic processing: radiation chemistry.

\subsection{Radiation chemistry of cosmic ices}

While low-temperature $(\sim 40 \mathrm{~K})$ thermal processing of organic ice mixtures to form more complex species has been demonstrated, ${ }^{14}$ photolysis/radiolysis of extraterrestrial ices is thought to be the primary path to prebiotic molecules in cosmic ices. Except for rare entities such as Titan which has an icy surface consisting of methane and ethane, the dominant component of extraterrestrial ices is water. Celestial ices, some containing organics, have been detected on solar-system bodies such as asteroids (e.g., 24 Themis), comets (e.g., 67P/ChuryumovGerasimenko), planets (e.g., Neptune), dwarf planets (e.g., Ceres), and moons (e.g., Europa). In addition, cosmic ices also include interstellar ices within dark, dense molecular clouds. These interstellar ices, having a thickness of a few hundred molecular layers, are composed of primarily of water $\left(\mathrm{H}_{2} \mathrm{O}\right)$, carbon dioxide $\left(\mathrm{CO}_{2}\right)$, methanol $\left(\mathrm{CH}_{3} \mathrm{OH}\right)$, and ammonia $\left(\mathrm{NH}_{3}\right)$ surrounding carbonaceous or silicaceous micron-size dust particles. ${ }^{15}$ Far (Deep)-UV $(200-300 \mathrm{~nm})$, nearUV $(300-400 \mathrm{~nm})$, and visible $(400-700 \mathrm{~nm})$ light are incident upon these cosmic ices and can initiate photochemistry. While photochemistry proceeds via electronic excitation by absorbed photons, radiation chemistry, by definition, involves ionization. In addition to condensed phase photochemistry, radiation chemistry in the condensed phase occurs in outer space because extraterrestrial ices are also continuously bombarded by high-energy particles (e.g., cosmic rays consisting mostly of protons) and high-energy photons (e.g., vacuum-UV (100-200 nm), extreme-UV (10-100 nm), X-rays, and $\gamma$-rays). Given that the ionization energy of a generic molecule is $\sim 10 \mathrm{eV}$ and that the ionization threshold is reduced in the condensed phase 
compared to the gas phase, Lyman alpha radiation $(10.2 \mathrm{eV})$ may result in ionization and subsequent radiation-induced chemistry. Results of numerous studies suggest that condensed phase radiolysis is mediated by low-energy $(<20 \mathrm{eV})$ electrons produced by the interaction of high-energy radiation with matter. ${ }^{16-18}$ The role of low-energy electrons in the radiolysis of cosmic ices has been recently reviewed..$^{19}$ Interestingly, in 2018, glycine formation was observed in $\mathrm{CO}_{2}: \mathrm{CH}_{4}: \mathrm{NH}_{3}$ ices irradiated by sub-ionization electrons. ${ }^{20}$

While in the sections below we focus on radiolysis of condensed ammonia, we note that several studies have identified hydrazine but not diazene as a radiolysis product of gaseous ammonia. $^{21-23}$

\subsection{High-Energy Ion Irradiation of Condensed Ammonia}

The high-energy $(\sim 500 \mathrm{MeV})$ heavy ion $\left({ }^{64} \mathrm{Ni}^{24+}\right.$ and $\left.{ }^{70} \mathrm{Zn}^{26+}\right)$ bombardment of pure ammonia ices has been studied to mimic some cosmic ray-induced processes. ${ }^{24}$ Molecular hydrogen $\left(\mathrm{H}_{2}\right)$, molecular nitrogen $\left(\mathrm{N}_{2}\right)$, cis-diazene $(\mathrm{HNNH})$, iso-diazene $\left(\mathrm{NNH}_{2}\right)$, hydrazine $\left(\mathrm{N}_{2} \mathrm{H}_{4}\right)$, azide ion $\left(\mathrm{N}_{3}^{-}\right)$, ammonium ion $\left(\mathrm{NH}_{4}^{+}\right)$, and ammonium azide salt $\left(\mathrm{NH}_{4}{ }^{+} \mathrm{N}_{3}{ }^{-}\right)$were all observed following high-energy ion irradiation of condensed pure ammonia (molecular structures shown in Figure 1). The sole radical reported was the amidogen (amido) radical $\left(\mathrm{NH}_{2}\right) .{ }^{24}$ Radiolysis by $0.8 \mathrm{MeV}$ protons of ammonia/water ices ${ }^{25}$ and by $144 \mathrm{keV} \mathrm{S}^{9+}$ ions of ammonia/carbon dioxide ${ }^{26}$ ices have also been studied.

\subsection{High-Energy Photon Irradiation of Condensed Ammonia}

Following irradiation of $\mathrm{NH}_{3}$ ice films by $150 \mathrm{eV}$ photons, results of Near-Edge X-ray Absorption Fine Structure (NEXAFS) spectroscopy confirmed the production of large amounts of $\mathrm{N}_{2}(12 \%)$, as well as cis-diazene $(\mathrm{HNNH})$, iso-diazene $\left(\mathrm{NNH}_{2}\right)$, azide $\left(\mathrm{N}_{3}{ }^{-}\right)$, and hydrazoic 
acid (hydrogen azide) $\left(\mathrm{HN}_{3}\right) .{ }^{27}$ Hydrazine was not detected in this study likely due to limitations associated with NEXAFS. ${ }^{27}$

\subsection{High-Energy Electron Irradiation of Condensed Ammonia}

The radiolysis of condensed ammonia, initiated by high-energy electrons, has been studied using post-irradiation temperature programmed desorption (TPD) experiments. ${ }^{28,29,30-31}$ Results of such experiments conducted following $5 \mathrm{keV}$ electron irradiation of ammonia ice films indicate the production of molecular nitrogen $\left(\mathrm{N}_{2}\right)$, molecular hydrogen $\left(\mathrm{H}_{2}\right)$, hydrazine $\left(\mathrm{N}_{2} \mathrm{H}_{4}\right)$, and diazene $\left(\mathrm{N}_{2} \mathrm{H}_{2}\right) \cdot{ }^{28}$ Based on the observation of peaks in $m / z=32\left(\mathrm{~N}_{2} \mathrm{H}_{4}{ }^{+}\right), m / z=31$ $\left(\mathrm{N}_{2} \mathrm{H}_{3}{ }^{+}\right), m / z=30\left(\mathrm{~N}_{2} \mathrm{H}_{2}{ }^{+}\right)$, and $m / z=29\left(\mathrm{~N}_{2} \mathrm{H}^{+}\right)$at $\sim 160 \mathrm{~K}$ in post-irradiation TPD experiments, hydrazine was identified as a product of high-energy electron irradiation of condensed ammonia. ${ }^{28}$ The presence of peaks in $m / z=30$ and 29 at temperatures above $160 \mathrm{~K}$, even after the $m / z=32$ and 31 signals had decreased to zero, was attributed to diazene. ${ }^{28}$ Hydrazoic acid $\left(\mathrm{HN}_{3}\right)$ was not detected in post-irradiation temperature programmed desorption experiments likely because it is thermally unstable, and decomposes at a lower temperature than its desorption temperature. ${ }^{28}$ Results of recent post-irradiation TPD experiments, employing reflectron time-of-flight mass spectrometry, indicate the production of triazane $\left(\mathrm{N}_{3} \mathrm{H}_{5}\right)$ and cyclotriazane/triazene $\left(\mathrm{N}_{3} \mathrm{H}_{3}\right)$ following $5 \mathrm{keV}$ electron irradiation of condensed ammonia. ${ }^{30-31}$

In addition to the aforementioned TPD measurements, infrared spectroscopy was used to verify the $5 \mathrm{keV}$ electron-induced production of both the cis- and iso- isomers of diazene from condensed ammonia. ${ }^{28}$ Trans-diazene formation could not be confirmed, probably because the vibrational features are too similar to those of ammonia. ${ }^{28}$ Two additional products, hydrazoic acid $\left(\mathrm{HN}_{3}\right)$ and the amidogen radical $\left(\mathrm{NH}_{2}\right)$, were identified through infrared spectroscopy in the same study. ${ }^{28}$ It is believed that hydrazine is not detectable in infrared studies as its signature 
bands overlap with those exhibited by ammonia, with the possible exception of a feature at 895 $\mathrm{cm}^{-1} \cdot 24,28$

In this article, we describe the dynamics of hydrazine and diazene production from the radiolysis of condensed ammonia by high-energy (1 keV) and low-energy (7-10 eV) electrons. First, we confirm the identification of these two radiolysis products by using three isotopologues $\left(\mathrm{NH}_{3}, \mathrm{ND}_{3}\right.$, and $\left.{ }^{15} \mathrm{NH}_{3}\right)$ of ammonia. Second, we demonstrate that electron-induced reactions likely occur in the multilayer and not on the metal surface based on qualitatively similar results obtained on both $\mathrm{Mo}(110)$ and $\mathrm{Ta}(110)$. Third, we provide experimental evidence consistent with two-step mechanisms that involve bimolecular steps for the electron-induced synthesis of hydrazine and diazene from condensed ammonia. Finally, we establish that hydrazine results from condensed phase reactions of ammonia initiated by electrons with incident energies as low as $7 \mathrm{eV}$, suggesting a role for dissociative electron attachment or electron impact excitation, or both. This observation is qualitatively consistent with the now widely accepted view that lowenergy electrons play a pivotal role in high-energy radiolysis.

\section{$2 \quad$ Experimental}

Experiments at Wellesley College were conducted in a custom-designed stainless steel ultrahigh vacuum (UHV) chamber, described in detail previously. ${ }^{32}$ The base pressure of the UHV chamber is maintained at $\sim 1 \times 10^{-9}$ Torr and is monitored with a nude ion gauge. In order to maintain ultrahigh vacuum pressures, a turbomolecular pump, rotary vane mechanical pump, ion pump, and titanium sublimation pump are employed. An electrically isolated single crystal ( $\mathrm{Ta}(110)$ or $\mathrm{Mo}(110))$ substrate inside the chamber is cooled via a liquid nitrogen reservoir to cryogenic temperatures of $\sim 90 \mathrm{~K}$. Surface temperature was monitored using a W/5\% Re vs. $\mathrm{W} / 26 \%$ Re thermocouple spot welded to the edge of the crystal. The crystal is fixed to a 
manipulator that is capable of $\theta, x, y$, and $z$ movement. Typically, experiments necessitated only rotation between the gas doser, electron gun, and mass spectrometer.

Samples of $\mathrm{NH}_{3}\left(99.99 \%\right.$, Matheson), $\mathrm{ND}_{3}$ (99 atom\% D, Cambridge Isotope Laboratories), and ${ }^{15} \mathrm{NH}_{3}$ (98 atom $\%{ }^{15} \mathrm{~N}$, Aldrich) were used without further purification. Films of were prepared by introducing gas samples first into a "manifold" or "dosing chamber," where pressure was measured by Baratron (MKS Instruments), and then via a precision leak valve, into the UHV chamber to condense upon the $\mathrm{Mo}(110) / \mathrm{Ta}(110)$ substrate. Sample film thickness, which for convenience is expressed in monolayers (ML) of ammonia, was varied by controlling the change in pressure within the dosing chamber during film deposition. The quantity of gas (i.e., pressure change) required to form $1 \mathrm{ML}$ was determined from temperature programed desorption measurements with unirradiated ammonia films. 1 ML was defined to be the maximum exposure of ammonia that did not yield a multilayer peak. This method to determine film thickness has been used in other laboratories studying cosmic ice analogs. ${ }^{33-34}$ Note, however, that the ML designation relates more properly to the quantity or mass of deposited $\mathrm{NH}_{3}$, rather than to the thickness of a film, which can vary with porosity and film order, both of which are dependent on substrate temperature and other parameters of film deposition.

Films were irradiated using a Kimball Physics FRA2X1-2 flood electron gun, at energies between $5 \mathrm{eV}$ and $1000 \mathrm{eV}$ and transmitted electron currents varying between $1.5 \mu \mathrm{A}$ and $35 \mu \mathrm{A}$, corresponding to electron fluxes of $1.9 \times 10^{13}$ electrons $\mathrm{cm}^{-2} \mathrm{~s}^{-1}$ and $4.4 \times 10^{14}$ electrons cm $\mathrm{cm}^{-1}$. The energy distribution of the electron gun has a FWHM of $\sim 0.4 \mathrm{eV}$. The entire $1 \mathrm{~cm}^{2}$ crystal was irradiated during electron irradiation.

The Mo(110) surface was cleaned by radiative heating using radiation emitted by a hot tungsten filament positioned immediately behind the metal crystal. Further heating by electron 
bombardment to $\sim 2200 \mathrm{~K}$ ensured the desorption of remaining nitrogen and hydrogen between experiments. Once daily, the surface was further cleaned of carbon by dosing oxygen $\left(5 \times 10^{-9}\right.$ Torr for five minutes) at $\sim 1200 \mathrm{~K}$ and subsequently heating to $\sim 2200 \mathrm{~K}$ to remove excess adsorbed oxygen. The $\mathrm{Ta}(110)$ substrate was cleaned by radiative and electron bombardment heating to $2200 \mathrm{~K}$ following each experiment.

Post-irradiation TPD experiments were conducted by radiatively heating the crystal surface from $\sim 90 \mathrm{~K}$ to $\sim 800 \mathrm{~K}$ while monitoring three to five mass spectral fragments of the desorbing species with a triple-filtered Hiden IDP Series 500 quadrupole mass spectrometer. TPD experiments conducted in the absence of electron irradiation served as control experiments.

Because surface temperatures below $90 \mathrm{~K}$ were not attainable at Wellesley College, additional experiments were conducted at the University of Sherbrooke under UHV conditions (at a base pressure $\sim 6 \times 10^{-11}$ Torr) in a previously described experimental system. ${ }^{35}$ Target films were formed by vapor deposition onto a Pt-foil substrate, the temperature of which can be controlled between 22 and $400 \mathrm{~K}$ with a closed-cycle He cryostat and resistive heating elements. ${ }^{36}$ The thickness of films in monolayers (ML) condensed onto the substrate was determined with an absolute accuracy of $\sim 30 \%$ by a volumetric dosing procedure similar to that described for the Wellesley experiments. ${ }^{37}$ A chromel-alumel thermocouple spot welded to the $\mathrm{Pt}$ foil facilitated the accurate measurement of film temperatures for TPD. The foil was cleaned between experiments by resistive heating to $\sim 1000 \mathrm{~K}$. For the experiments described in this work, $\mathrm{NH}_{3}$ (99.9\% MSD isotopes) was deposited on the Pt-foil substrate cooled to $22 \mathrm{~K}$. Sample films were irradiated isothermally at $22 \mathrm{~K}$ with electrons of specific energies from an electron gun (Kimball Physics ELG-2). The energy resolution of this electron beam is approximately 0.5 
$\mathrm{eV}$. For post-irradiation TPD measurements, the entire film was irradiated in raster-mode (1.25 $\times 10^{12}$ electrons $\mathrm{cm}^{-2} \mathrm{~s}^{-1}$ flux onto a sample of $1 \mathrm{~cm}^{2}$ ).

For TPD measurements, desorbing species were ionized and detected with a quadrupole mass spectrometer (Extrel 150-QC). Samples on the Pt foil were heated resistively by currents of up to 7 A delivered by a floatable power supply (Kepco ATE 25-10M). The latter was controlled by an in-house LabVIEW program to provide a typical linear heating rate of $10 \mathrm{~K} \mathrm{~min}^{-1}$. The mass spectrometer ionizer is off during electron-beam irradiation and requires $\sim 30$ minutes to stabilize once it is turned on. During this period, samples (i.e., both irradiated and unirradiated films) are rotated away from the mass spectrometer and are biased at $-87 \mathrm{~V}$ relative to ground, to repel electrons from the ionizer of the mass spectrometer. This sample bias is maintained once samples are returned into position and throughout the heating process.

\section{Results and Discussion}

\subsection{Identification of Hydrazine and Diazene}

Hydrazine $\left(\mathrm{N}_{2} \mathrm{H}_{4}\right)$ identification was based on results of TPD experiments conducted after $1000 \mathrm{eV}$ electron irradiation of condensed ammonia $\left(\mathrm{NH}_{3}\right)$, showing desorption peaks at $155 \mathrm{~K}$ for $m / z=32\left(\mathrm{~N}_{2} \mathrm{H}_{4}{ }^{+}\right), 30\left(\mathrm{~N}_{2} \mathrm{H}_{2}{ }^{+}\right)$, and $29\left(\mathrm{~N}_{2} \mathrm{H}^{+}\right)$(Figure 1). ${ }^{\mathrm{b}}$ The peak associated with $m / z$ $=32\left(\mathrm{~N}_{2} \mathrm{H}_{4}^{+}\right)$is the largest, consistent with this fragment being the dominant ion in the published hydrazine mass spectrum. ${ }^{38}$ The identification of hydrazine was further verified by isotopic labeling experiments whose results show the expected shift to $m / z=36\left(\mathrm{~N}_{2} \mathrm{D}_{4}{ }^{+}\right), 34\left(\mathrm{~N}_{2} \mathrm{D}_{3}{ }^{+}\right)$, and $32\left(\mathrm{~N}_{2} \mathrm{D}_{2}{ }^{+}\right)$in irradiated deuterated ammonia $\left(\mathrm{ND}_{3}\right)$ (Supporting Information: Figure B: postirradiation TPD of $\left.\mathrm{ND}_{3}\right)$ as well as $m / z=34\left({ }^{15} \mathrm{~N}_{2} \mathrm{H}_{4}{ }^{+}\right), 32\left({ }^{15} \mathrm{~N}_{2} \mathrm{H}_{2}{ }^{+}\right)$, and $31\left({ }^{15} \mathrm{~N}_{2} \mathrm{H}^{+}\right)$in

\footnotetext{
${ }^{\mathrm{b}}$ We attribute to ion-molecule reactions of ammonia in the mass spectrometer the observed peaks at $\sim 115 \mathrm{~K}$ for all monitored mass spectral fragments. These peaks appear because of the significant amount of ammonia present in our films. The ion-molecule reactions of ammonia are also detected in unirradiated films (data shown in Supporting Information, Figure $\mathrm{A}$ : TPD of unirradiated $\mathrm{ND}_{3}$ films).
} 
irradiated ${ }^{15} \mathrm{NH}_{3}$ (Supporting Information: Figure C: post-irradiation TPD of ${ }^{15} \mathrm{NH}_{3}$ ). As discussed previously, prior studies have also identified hydrazine as a high-energy radiolysis ( $550 \mathrm{MeV}$ energy ions ${ }^{24}$ and $5 \mathrm{keV}$ electrons ${ }^{28}$ ) product of ammonia.

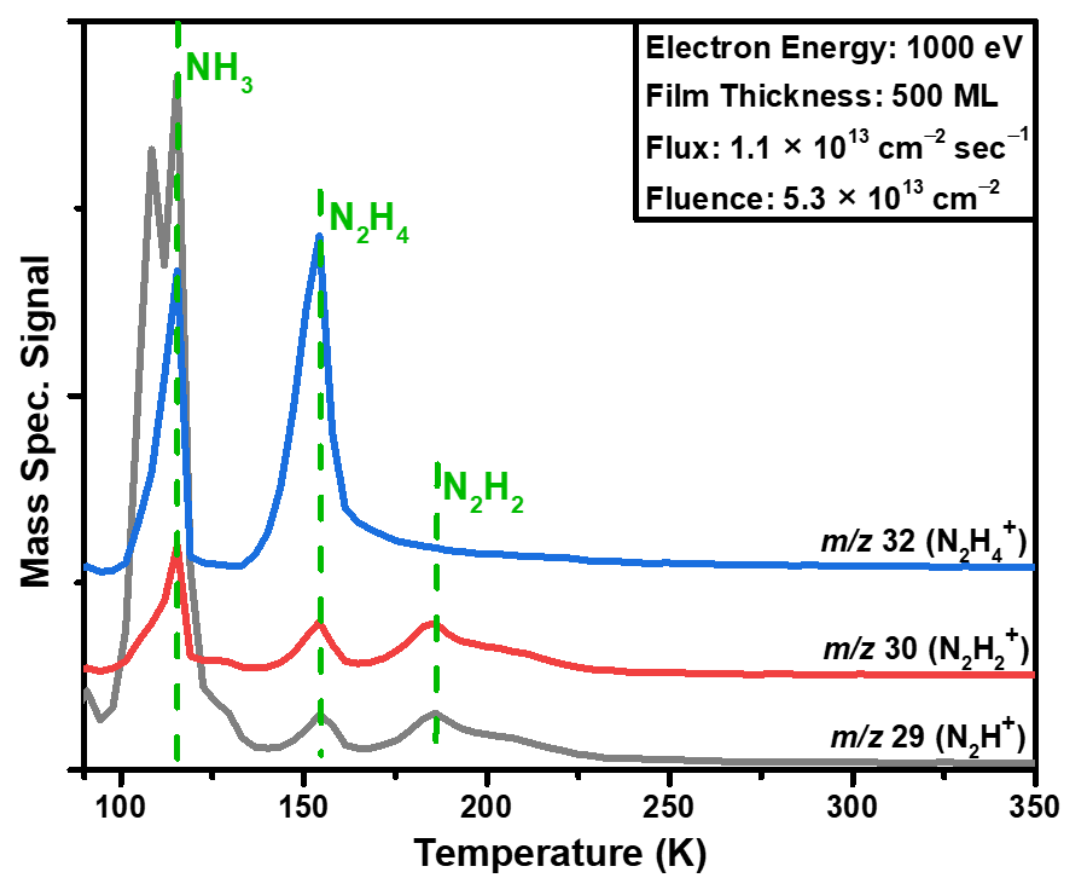

Figure 1

Results showing production of hydrazine and diazene in temperature-programmed desorption experiments conducted after high-energy electron irradiation of a $500 \mathrm{ML}$ film of condensed $\mathrm{NH}_{3}$ on a $\mathrm{Mo}(110)$ surface. The peaks at $\sim 115 \mathrm{~K}$ attributed to ammonia are due to ion-molecule reactions in the ionizer of the mass spectrometer, as verified by separate temperature programmed desorption experiments in which $\mathrm{m} / \mathrm{z}=17$ was monitored.

Diazene $\left(\mathrm{N}_{2} \mathrm{H}_{2}\right)$ identification was based on the results of the same experiment, showing desorption peaks at $\sim 185 \mathrm{~K}$ for $m / z=30\left(\mathrm{~N}_{2} \mathrm{H}_{2}{ }^{+}\right)$and $29\left(\mathrm{~N}_{2} \mathrm{H}^{+}\right)$(Figure 1). Because the parent ion of diazene is $m / z=30\left(\mathrm{~N}_{2} \mathrm{H}_{2}{ }^{+}\right)$, the lack of desorption peaks at $\sim 185 \mathrm{~K}$ for $32\left(\mathrm{~N}_{2} \mathrm{H}_{4}^{+}\right)$ provides additional support for our identification of diazene. Results of post-irradiation experiments involving isotopically labeled ammonia were used to verify our identification of diazene. We observe the expected mass spectral fragment shifts to $m / z=36\left(\mathrm{~N}_{2} \mathrm{D}_{4}{ }^{+}\right), m / z=34$ $\left(\mathrm{N}_{2} \mathrm{D}_{3}{ }^{+}\right)$and $32\left(\mathrm{~N}_{2} \mathrm{D}_{2}{ }^{+}\right)$in irradiated $\mathrm{ND}_{3}$ (Supporting Information: Figure B: post-irradiation 
TPD of $\mathrm{ND}_{3}$ ) and to $m / z=31\left({ }^{15} \mathrm{~N}_{2} \mathrm{H}^{+}\right)$and $32\left({ }^{15} \mathrm{~N}_{2} \mathrm{H}_{2}{ }^{+}\right)$in irradiated ${ }^{15} \mathrm{NH}_{3}$ (Supporting Information: Figure C: post-irradiation TPD of $\left.{ }^{15} \mathrm{NH}_{3}\right)$. Diazene $\left(\mathrm{N}_{2} \mathrm{H}_{2}\right)$ has been identified previously as a high-energy radiolysis product of condensed ammonia. ${ }^{24,27-28}$

To investigate the role of the metal substrate surface, ammonia radiolysis experiments were conducted with both $\mathrm{Mo}(110)$ and $\mathrm{Ta}(110)$ crystals. Both hydrazine and diazene were detected during TPD experiments following electron-induced radiolysis of ammonia films regardless of the substrate. Furthermore, the TPD peaks for both hydrazine and diazene appear qualitatively similar for $\mathrm{Mo}(110), \mathrm{Ta}(110)$, and polished polycrystalline silver, ${ }^{28,30-31}$ suggesting that the substrate surface plays a minimal, if any, role in the results reported in this study.

\subsection{Proposed Radiolysis Mechanisms for Hydrazine and Diazene Formation}

From the results of high-energy electron and photon irradiation of condensed ammonia, several mechanisms have been suggested for the formation of particular radiolysis products. Most notably, hydrazine is expected from the dimerization of two amidogen radicals $\left(\mathrm{NH}_{2}\right) .^{27-28}$

$$
\mathrm{NH}_{2}+\mathrm{NH}_{2} \rightarrow \mathrm{N}_{2} \mathrm{H}_{4}
$$

As described previously, following irradiation of condensed ammonia by $5 \mathrm{keV}$ electrons, the amidogen radical has been identified by post-irradiation infrared spectroscopy. ${ }^{28}$ As described in detail below, (1) dissociative electron attachment, (2) electronic excitation, and (3) dissociative ionization likely play a role in the synthesis of amidogen radicals during condensed phase ammonia radiolysis.

The radiolytic production of amidogen radicals from ammonia may proceed via dissociative electron attachment resonances at incident electron energies of $\sim 6$ and $\sim 10 \mathrm{eV}$ in the production $\mathrm{H}^{-} / \mathrm{D}^{-}$: 


$$
\mathrm{NH}_{3}+e^{-} \rightarrow \mathrm{H}^{-}+\mathrm{NH}_{2}
$$

The hydride anion $\left(\mathrm{H}^{-}\right)$is the dominant product of the interactions of low-energy electrons with gaseous ammonia. ${ }^{39-40}$ In the electron stimulated desorption of deuterated ammonia condensed on a platinum substrate, low-energy electron irradiation primarily yielded $\mathrm{D}^{-}$anions in a process also attributed to dissociative electron attachment. ${ }^{41}$ The production of $\mathrm{H}^{-}$ions during highenergy $(150 \mathrm{eV})$ electron stimulated desorption from one-monolayer thick ammonia films may also involve dissociative electron attachment via low-energy secondary electrons produced by $150 \mathrm{eV}$ electrons interacting with the metal surface. ${ }^{42}$ Because gas and condensed phase ammonia demonstrate resonances in the production/desorption of the $\mathrm{H}^{-} / \mathrm{D}^{-}$ion, concomitant resonances should exist in the electron-induced production of the complementary amidogen radical $\left(\mathrm{NH}_{2} / \mathrm{ND}_{2}\right)$.

During radiolysis, in addition to dissociative electron attachment, we hypothesize that low-energy secondary electrons produced within bulk ammonia ice may induce electronic excitation, leading to the production of ground state amidogen radicals:

$$
\mathrm{NH}_{3} \stackrel{\mathrm{e}^{-}}{\longrightarrow} \mathrm{NH}_{2}\left(\tilde{\mathrm{X}}^{2} \mathrm{~B}_{1}\right)+\mathrm{H}
$$

The above electron-induced excitation process is a viable mechanism for the production of amidogen radicals given the energy threshold of $4.6 \mathrm{eV}$ for the analogous gas-phase spin-allowed photon-induced excitation process: ${ }^{43}$

$$
\mathrm{NH}_{3}+h v \rightarrow \mathrm{NH}_{2}\left(\tilde{\mathrm{X}}^{2} \mathrm{~B}_{1}\right)+\mathrm{H}
$$


Following electron impact excitation, another available molecular dissociation process is dipolar dissociation, the process by which the resultant excited electronic state induces ion-pair formation.

The electron-induced dissociative ionization of ammonia may also produce $\mathrm{NH}_{2}$ radicals. Results of electron stimulated desorption studies indicate the formation of $\mathrm{H}^{+}$as the primary positive ion formed during high-energy $(1.5 \mathrm{keV})$ electron irradiation of ten-monolayer (ML) thick ammonia films adsorbed on an argon spacer layer: ${ }^{44}$

$$
\begin{gathered}
\mathrm{NH}_{3}+e^{-} \rightarrow \mathrm{NH}_{3}^{+}+2 e^{-} \\
\mathrm{NH}_{3}^{+} \rightarrow \mathrm{H}^{+}+\mathrm{NH}_{2}
\end{gathered}
$$

As shown above, the formation of $\mathrm{H}^{+}$from ionized ammonia involves the concomitant production of $\mathrm{NH}_{2}$ radicals. Proton transfer (acid-base chemistry) is another route for the synthesis of $\mathrm{NH}_{2}$ radicals via dissociative ionization of ammonia:

$$
\mathrm{NH}_{3}^{+}+\mathrm{NH}_{3} \rightarrow \mathrm{NH}_{2}+\mathrm{NH}_{4}^{+}
$$

Based on ultraviolet photoelectron spectra which show a $1.2 \mathrm{eV}$ energy shift upon ammonia condensation, ${ }^{45}$ we estimate that the above dissociative ionization mechanism has an electron energy threshold of $\sim 8.9 \mathrm{eV}$, which is less than the gas phase ionization energy of $10.1 \mathrm{eV}$ for ammonia.

Given the copious numbers of low-energy $(<20 \mathrm{eV})$ electrons produced during high-energy radiolysis, ${ }^{46}$ low-energy secondary electron-induced processes (dissociative electron attachment, electron impact excitation, and electron impact ionization) likely play a critical role in the 
condensed phase radiolysis of ammonia to form hydrazine via the dimerization of two amidogen radicals.

In contrast to hydrazine formation, according to a recent study involving $5 \mathrm{keV}$ irradiation of condensed ammonia, diazene formation via the dimerization of two imine (NH) (imidogen) radicals was considered unlikely because the photon-induced gas phase formation of the $\mathrm{NH}$ radical ground $\mathrm{X}^{3} \Sigma^{-}$state from ammonia is spin-forbidden. ${ }^{28}$

$$
\mathrm{NH}_{3}+h v \rightarrow \mathrm{NH}\left(\mathrm{X}^{3} \Sigma^{-}\right)+\mathrm{H}_{2}
$$

Therefore, high-energy electron-induced diazene formation from condensed ammonia was attributed to the excitation of the hydrazine product to an unstable electronic state, followed by the removal of two hydrogen atoms: ${ }^{28}$

$$
\begin{aligned}
& \mathrm{NH}_{2}+\mathrm{NH}_{2} \rightarrow\left[\mathrm{N}_{2} \mathrm{H}_{4}\right]^{*} \\
& {\left[\mathrm{~N}_{2} \mathrm{H}_{4}\right]^{*} \rightarrow \mathrm{N}_{2} \mathrm{H}_{2}+\mathrm{H}_{2}}
\end{aligned}
$$

An additional mechanism was proposed for the high-energy photon-induced formation of diazene from condensed ammonia. This radiolysis mechanism involves the $\mathrm{N}_{2} \mathrm{H}_{3}$ intermediate either reacting with itself or with an amidogen radical. ${ }^{27}$

Here, we propose, however, that the electron-induced condensed-phase production of diazene from the dimerization of two NH radicals is possible even though the photon-induced formation of the $\mathrm{NH}$ radical ground $\mathrm{X}^{3} \Sigma^{-}$state from gas phase ammonia is spin-forbidden. For example, the photon-induced formation of the excited $\mathrm{NH}\left(\mathrm{a}^{1} \Delta\right)$ from gaseous ammonia is spinallowed with a threshold photon energy of $5.7 \mathrm{eV} .{ }^{43}$ The photochemistry of gaseous ammonia may even produce excited imine radicals (e.g., $\mathrm{NH}\left(\mathrm{A}^{3} \Pi\right)$ ) via spin-forbidden transitions. ${ }^{43}$ 
More importantly, in general, electron-molecule interactions are not limited by spin conservation, as shown explicitly for ammonia. ${ }^{47}$ Because the electron-induced formation from ammonia of ground state and excited state imine radicals is likely, we suggest that radiolysis of condensed ammonia likely includes diazene formation via the dimerization of two imine (NH) radicals.

Although we are unable to make a distinction between yields formed by direct electron impact during irradiation and products formed during the heating stage after irradiation, it must be noted that diffusion of heavy radicals has been found at temperatures as low as $\sim 35 \mathrm{~K}^{15}$ Therefore, we expect that products observed in TPD experiments were formed during electron irradiation at $90 \mathrm{~K}$.

In the sections below, we provide experimental evidence that is consistent with the dimerization of $\mathrm{NH}_{2}$ and $\mathrm{NH}$ radicals producing $\mathrm{N}_{2} \mathrm{H}_{4}$ and $\mathrm{N}_{2} \mathrm{H}_{2}$, respectively. Specifically, we investigate the dependence of radiolysis yield on film characteristics (thickness and temperature) and irradiation parameters (electron energy, fluence, and flux).

\subsection{Radiolysis yield as a function of film thickness}

Results of post-irradiation TPD experiments conducted following irradiation at constant electron energy, electron flux, and electron fluence indicate that the yields of both hydrazine and diazene increase monotonically with increasing ammonia $\left(\mathrm{ND}_{3}\right)$ film thickness. To quantify the yield of hydrazine $\left(\mathrm{N}_{2} \mathrm{D}_{4}\right)$, the $m / z=36$ peak was integrated and the area under the curve was plotted against film thickness (Figure 3). The thinnest ammonia film in which hydrazine was detected was 15 monolayers. Because the first five data points show a semiquantitative quadratic relationship between hydrazine yield and the number of irradiated $\mathrm{NH}_{3}$ molecules, this data is suggestive of a bimolecular reaction mechanism for the production of hydrazine. We attribute the 
lack of quantitative agreement between the model and the experimental data to three factors: (1) difficulty in quantifying the role of the metal surface in quenching radiolytic processes in thin $(<$ $25 \mathrm{ML}$ ) films; ${ }^{48}(2)$ the possible desorption of $\mathrm{NH}_{2}$ radicals during irradiation from $90 \mathrm{~K}$ ammonia ices that are thin (see below); and (3) the finite electron range, the straight-line penetration distance, in condensed ammonia causes the hydrazine yield to begin to saturate as the film thickness is increased beyond 25 monolayers. While the electron range is not available for solid $\mathrm{NH}_{3}$, many solids exhibit electron ranges for $1 \mathrm{keV}$ electrons of between 20 and $100 \mathrm{~nm}$ (or approximately between 50 and $250 \mathrm{ML} .{ }^{49}$ The finite electron range in liquid water is calculated to be on the order of $10 \mathrm{~nm} .{ }^{50}$

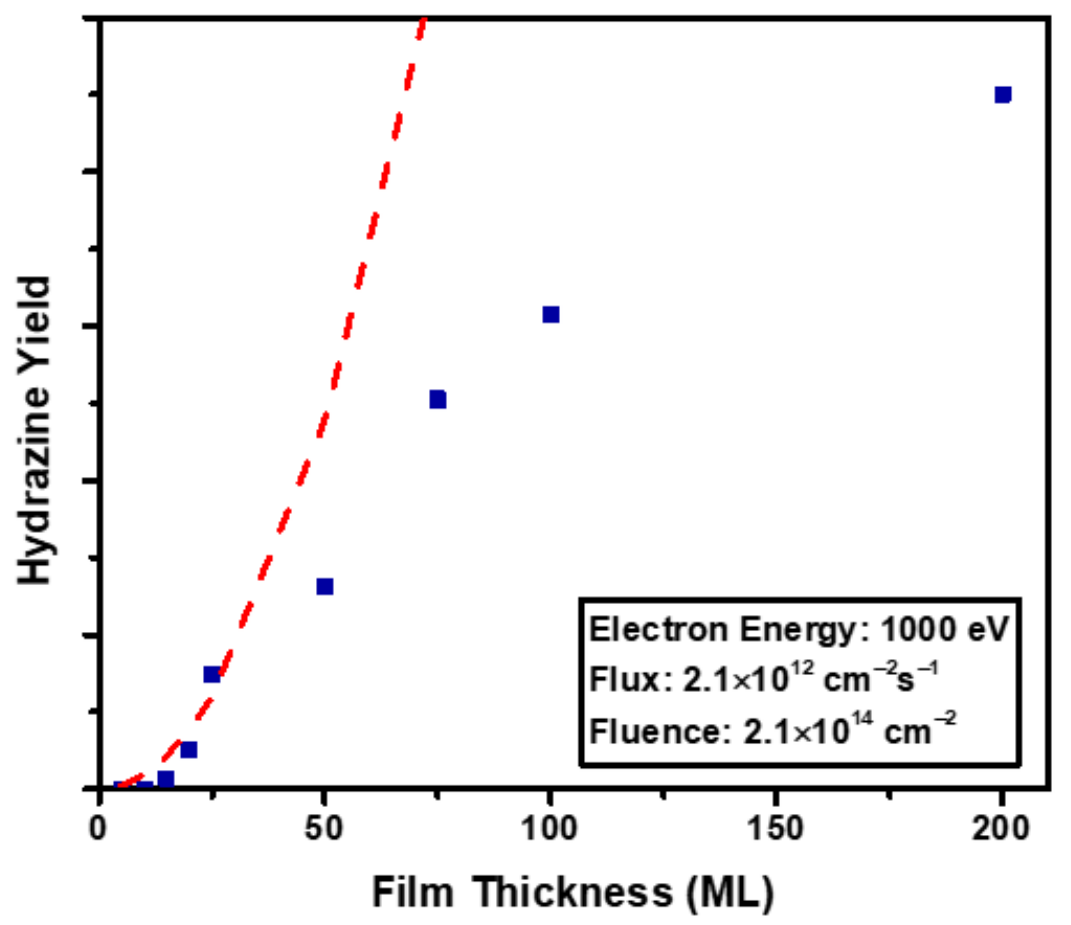

Figure 2

Hydrazine $\left(\mathrm{N}_{2} \mathrm{D}_{4}\right)$ yield monitored as a function of ammonia $\left(\mathrm{ND}_{3}\right)$ film thickness on $\mathrm{Ta}(110)$ surface. The first five data points were fit to a quadratic equation (red).

The quantification of diazene required additional calculations to ensure that the integration of the $m / z=32$ curve did not include any contribution from hydrazine (Figure 3 ). 
This separation was accomplished by first multiplying the $m / z=36$ curve by a factor such that this modified curve and the $m / z=32$ curve would match for the first desorption peak. Finally, the area under the modified $m / z=36$ curve was subtracted from the area under the $m / z=32$ curve in order to quantify the area that was exclusive to the diazene product.

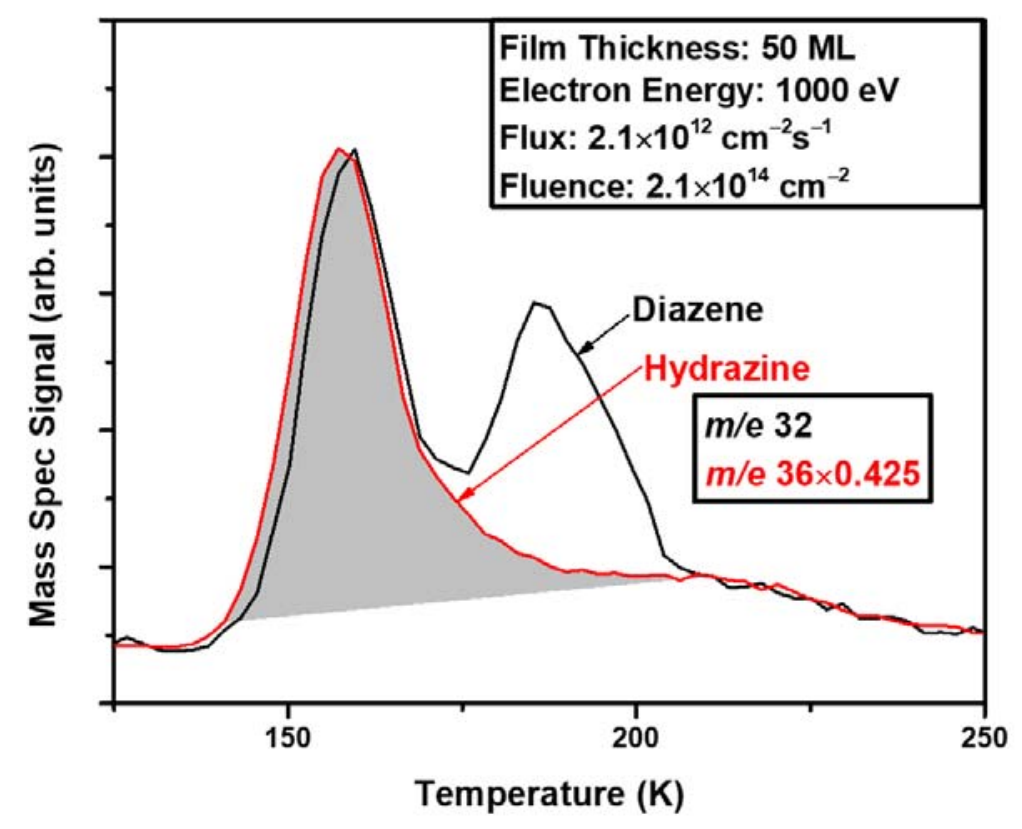

Figure 3

Calculating diazene yield from post-irradiation TPD data. The $m / e=36$ mass spectra curve is multiplied by some factor in order to overlay its hydrazine peak at $124 \mathrm{~K}$ with its fragment peak in $m / e=32$. The area under the $m / e=36$ curve is subtracted from the area under the $m / e=32$ curve. The gray color region shown corresponds to the hydrazine product. The white region between the black and red curves corresponds to the diazene product.

The yield of diazene as a function of film thickness (Figure 4) is also suggestive of a reaction mechanism involving a bimolecular step for the formation of diazene from two NH radicals. 


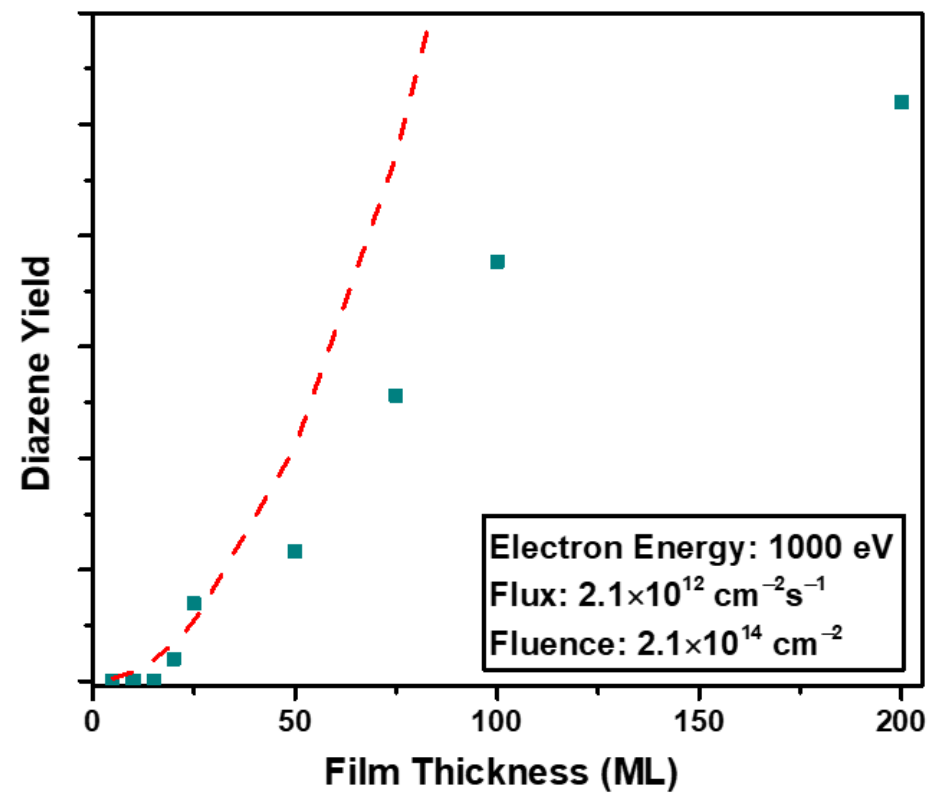

Figure 4

Diazene $\left(\mathrm{N}_{2} \mathrm{D}_{4}\right)$ yield monitored as a function of ammonia $\left(\mathrm{ND}_{3}\right)$ film thickness on $\mathrm{Ta}(110)$ surface. The first five data points were fit to a quadratic equation (red). 


\subsection{Radiolysis yield as a function of fluence}

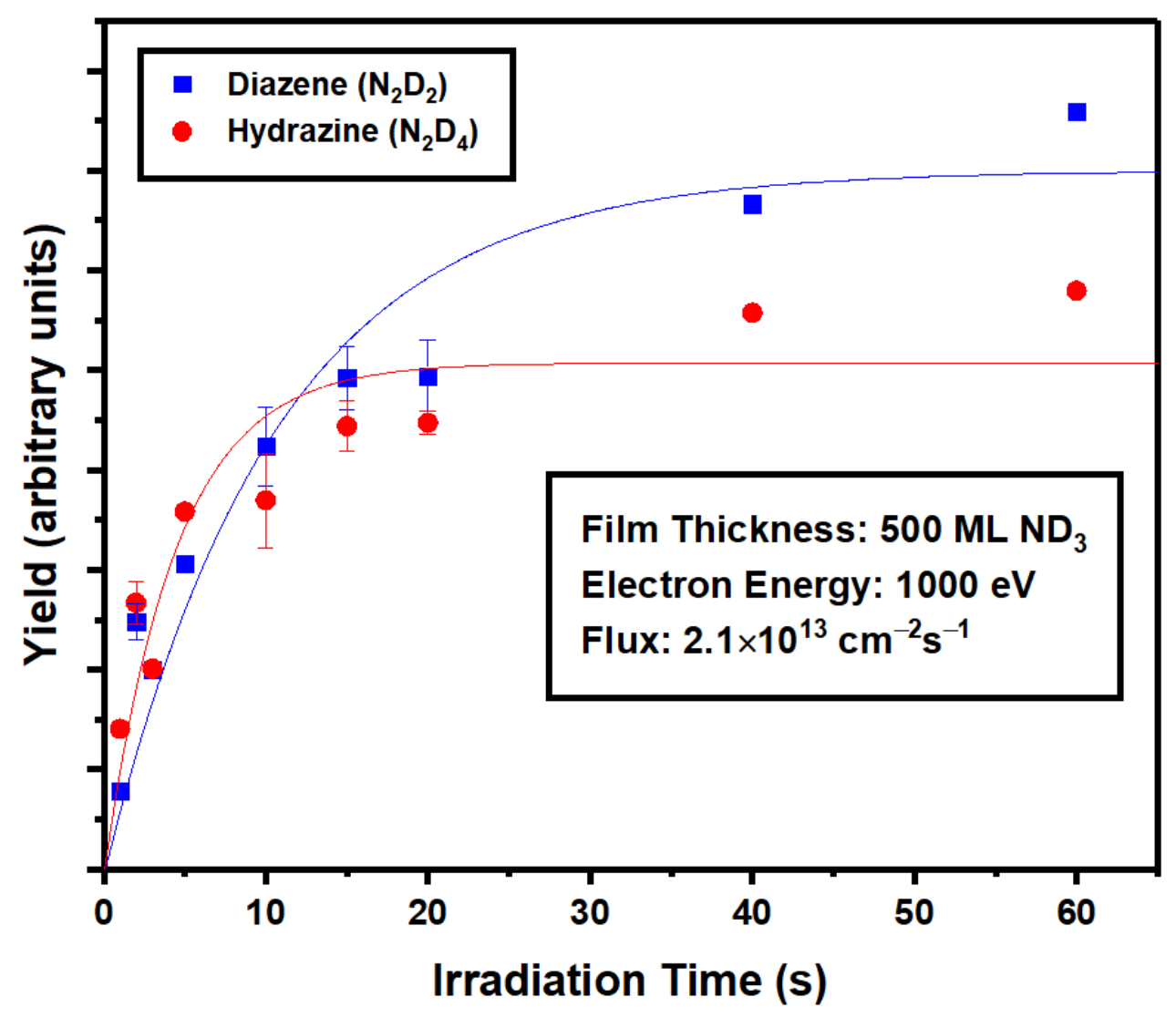

Figure 5

Hydrazine (blue) and diazene (red) yields as a function of fluence. The yields of hydrazine and diazene were obtained by integrating areas under the $m / z=36$ and 32 peaks, respectively. The $m / z=32$ peak area was corrected as shown in Figure 3. $\mathrm{ND}_{3}$ films (500 monolayers) were irradiated with $1000 \mathrm{eV}$ electrons. Irradiation times were varied from 1 second to 60 seconds while the incident current was kept constant. The error bars represent standard deviations of the mean. The curves represent fits to a model described in the text.

The yield of hydrazine and diazene was monitored as a function of fluence (Figure 5) at constant film thickness by maintaining a constant electron flux $\left(4.1 \times 10^{13}\right.$ electrons $\left.\mathrm{cm}^{-2} \mathrm{~s}^{-1}\right)$ while varying the irradiation times. The yield functions demonstrate a high degree of similarity for irradiation times shorter than $20 \mathrm{sec}\left(8.1 \times 10^{14}\right.$ electrons $\left.\mathrm{cm}^{-2}\right)$. We attempted to fit the data using a two-step kinetic model, involving a bimolecular radical-radical dimerization between amidogen/imine radicals, as the formation mechanism for hydrazine/diazene: 


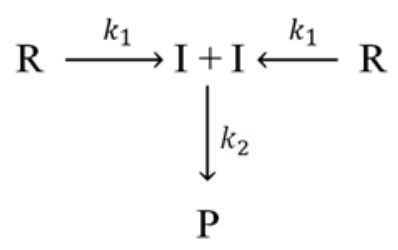

In the above reaction mechanism, $\mathrm{R}$ represents the reactant ammonia, $\mathrm{I}$ is an intermediate species $\left(\mathrm{NH}_{2}\right.$ or $\left.\mathrm{NH}\right)$, and $\mathrm{P}$ is the product (either hydrazine or diazene). Differential equations can be written for each step of this proposed mechanism:

$$
\begin{gathered}
\frac{d[\mathrm{R}]}{d t}=-k_{1}[\mathrm{R}] \\
\frac{d[\mathrm{I}]}{d t}=k_{1}[\mathrm{R}]-k_{2}[\mathrm{I}]^{2} \\
\frac{d[\mathrm{P}]}{d t}=\frac{k_{2}}{2}[\mathrm{I}]^{2}
\end{gathered}
$$

In the above equations, $k_{1}=F \sigma$, where $F$ is the electron flux (electrons $\mathrm{cm}^{-2} \mathrm{~s}^{-1}$ ) and $\sigma$ is the total effective electron-induced degradation cross section. These coupled differential equations were solved numerically to generate the fits for the yields of hydrazine and diazene vs. electron fluence (Figure 5). We attribute the lack of quantitative agreement between the model and the experimental data to two factors: (1) the loss of product from the film during irradiation and (2) heating of the film prior to product quantification. Nevertheless, we suggest that the semiquantitative agreement between our experimental data and the kinetic model is consistent with the two-step dimerization reaction mechanism proposed for the electron-induced formation of hydrazine and diazene from condensed ammonia. Although one must be cautious about overinterpreting parameters gleaned from such kinetic solid-state models involving coupled differential equations, we suggest a diazene formation model that is simpler than what has been 
previously proposed. ${ }^{28}$ The dependence of the diazene yield on fluence is not consistent with an insertion reaction:

$$
\mathrm{NH}+\mathrm{NH}_{3} \rightarrow \mathrm{N}_{2} \mathrm{H}_{4}
$$

\subsection{Radiolysis yield as a function of incident electron energy}

Interestingly, hydrazine formation has been recently observed following $15 \mathrm{eV}$ electron irradiation of condensed ammonia. ${ }^{51}$ Because our ultimate goal is to determine the role of lowenergy electrons in the radiolysis of ammonia under astrochemically relevant conditions, we conducted TPD experiments following irradiation at lower incident electron energies. The lowest incident electron energy at which hydrazine and diazene production were consistently observed was $10 \mathrm{eV}$ (Figure 6) at an ice temperature of $90 \mathrm{~K}$, the lowest possible surface temperature attainable in the ultrahigh vacuum chamber at Wellesley College. These experiments involved four hours of electron irradiation. Even though a much higher fluence was used for the $10 \mathrm{eV}$ experiments, the yield of hydrazine and diazene was considerably smaller than that for the 1000 eV electrons. 


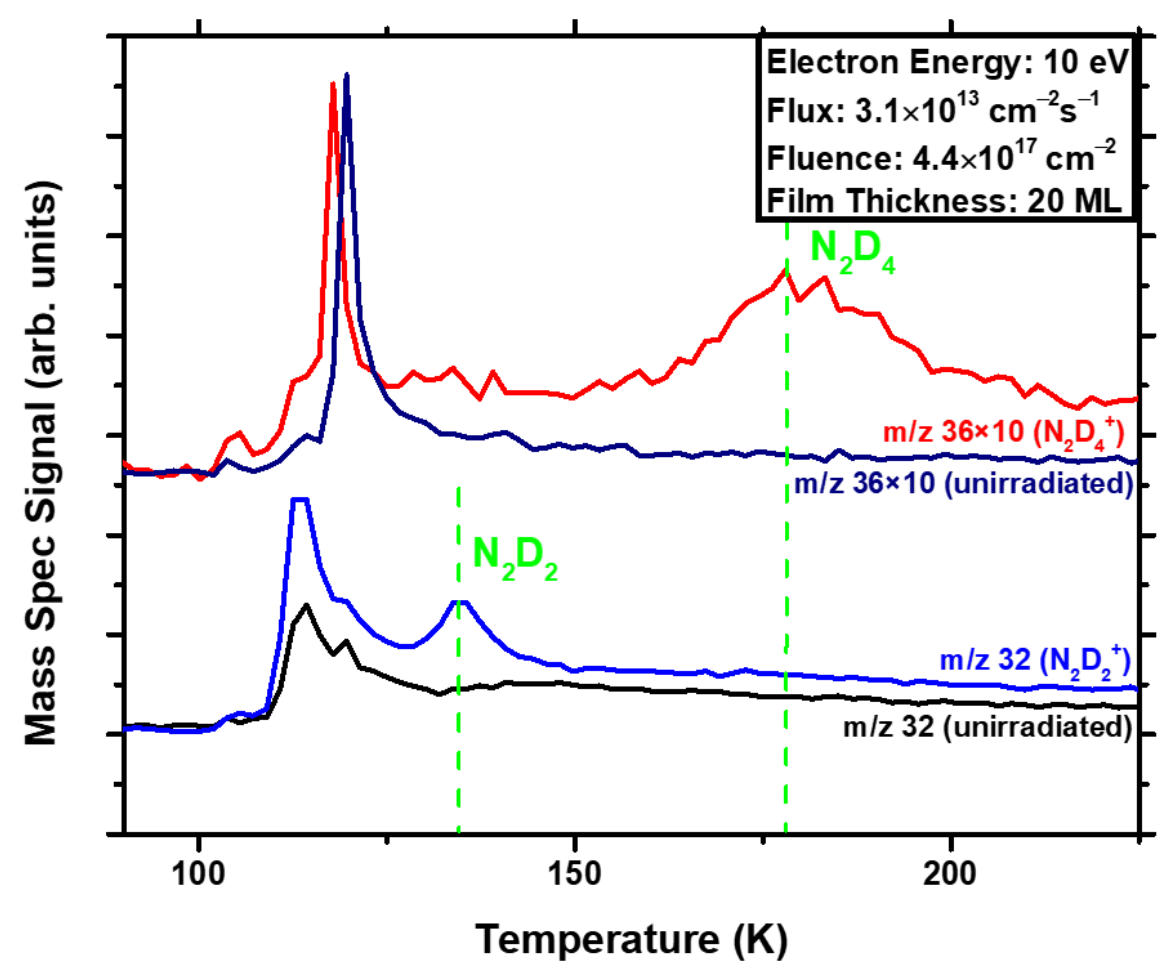

Figure 6

Post-irradiation TPD data following the irradiation of a 20 monolayer $\mathrm{ND}_{3}$ film at $90 \mathrm{~K}$ with $10 \mathrm{eV}$ electrons

Results of post-irradiation TPD experiments conducted at the University of Sherbrooke provide evidence for the formation of hydrazine from ammonia ices at $22 \mathrm{~K}$ at incident electron energies as low as $7 \mathrm{eV}$ (Figure 7). The production of hydrazine from condensed ammonia at sub-ionization electron energies suggests a role for one or both of electron impact excitation or dissociative electron attachment. These results are qualitatively compatible with the widelyaccepted hypothesis that condensed phase radiolysis is mediated by low-energy electrons produced by the interaction of high-energy radiation with matter. 


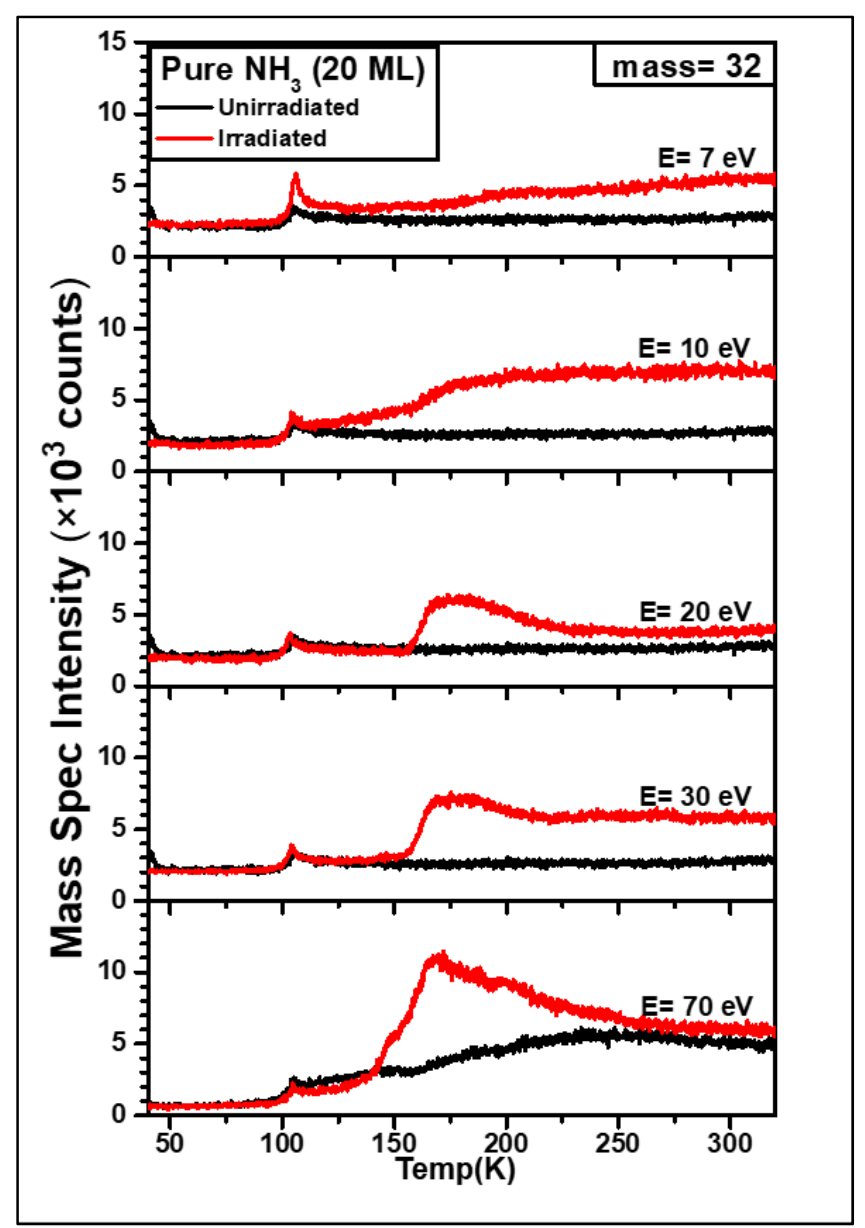

Figure 7

Post-irradiation TPD data following the irradiation of 20 monolayer $\mathrm{NH}_{3}$ films with electrons with the indicated energies. Note that for measurements at 7 and $10 \mathrm{eV}$, the electron fluence was $\sim 2.5 \times 10^{18}$ electrons $\mathrm{cm}^{2}$ at a flux of $\sim 6.9 \times 10^{14}$ electrons $\mathrm{cm}^{-2} \mathrm{~s}^{-1}$. At higher energies the fluence was $\sim 3.8 \times 10^{18} \mathrm{~cm}^{-2}$ at a flux of $\sim 1.1 \times 10^{15}$ electrons $\mathrm{cm}^{-2} \mathrm{~s}^{-1}$.

\subsection{Radiation yield as a function of ice temperature}

The influence of the ice temperature on ammonia radiolysis yield was investigated via TPD experiments conducted following $15 \mathrm{eV}$ electron irradiation of ammonia ices at 22 and $77 \mathrm{~K}$

(Figure 8). This reduction in hydrazine yield with increasing ice temperature could be related to an increased desorption rate for $\mathrm{NH}_{2}$ intermediates at temperatures approaching that of ammonia sublimation. Our attempt to measure electron stimulated $\mathrm{NH}_{2}$ desorption at low and high 
temperatures were hampered because the elevated partial pressure of $\mathrm{NH}_{3}$ and small variations in film temperature around $\sim 77 \mathrm{~K}$ led to a large and constantly varying background signal for $m / z=16$. The reduction in hydrazine yield with increasing temperature could also be related to decreased dimerization of $\mathrm{NH}_{2}$ species because of temperature-related changes in film morphology, porosity, and order. For example, the yields of $\mathrm{D}_{2}, \mathrm{O}_{2}$ and $\mathrm{D}_{2} \mathrm{O}_{2}$ in electron irradiated films of $\mathrm{D}_{2} \mathrm{O}$ were found to be higher from porous amorphous samples, than from dense, crystalline ones ${ }^{52}$ It was suggested that such behavior might be the result of lower recombination rates of dissociated molecules due to diffusion into pores, or due to the presence of L-defects in amorphous ice that may favor the formation of $\mathrm{D}_{2} \mathrm{O}_{2}$. The effects of film order and porosity thus merit further attention in a future study. Because higher temperatures likely lead to lower rate of $\mathrm{N}_{2} \mathrm{H}_{4}$ production and lower electron energies yield fewer radicals at equivalent fluxes, this radiolysis yield dependence on ice temperature likely contributes to the absence of detectable radiolysis products following electron irradiation of $90 \mathrm{~K}$ ammonia ices at an incident electron energy of $7 \mathrm{eV}$ (data not shown). The longer electron range ${ }^{\mathrm{c}}$ of higher energy electrons ${ }^{53}$ enhances the production of radical intermediates below the ice surface, facilitating the dimerization of $\mathrm{NH}_{2}$ and $\mathrm{NH}$ intermediates to form hydrazine and diazene, respectively.

\footnotetext{
${ }^{c}$ Electron range, the straight-line penetration distance of electrons in matter, is typically calculated by using the continuous slowing down approximation (CSDA). Reference 50 shows that the electron range can increase by two or three orders of magnitude when the electron energy is increased from $10 \mathrm{eV}$ to $1000 \mathrm{eV}$.
} 


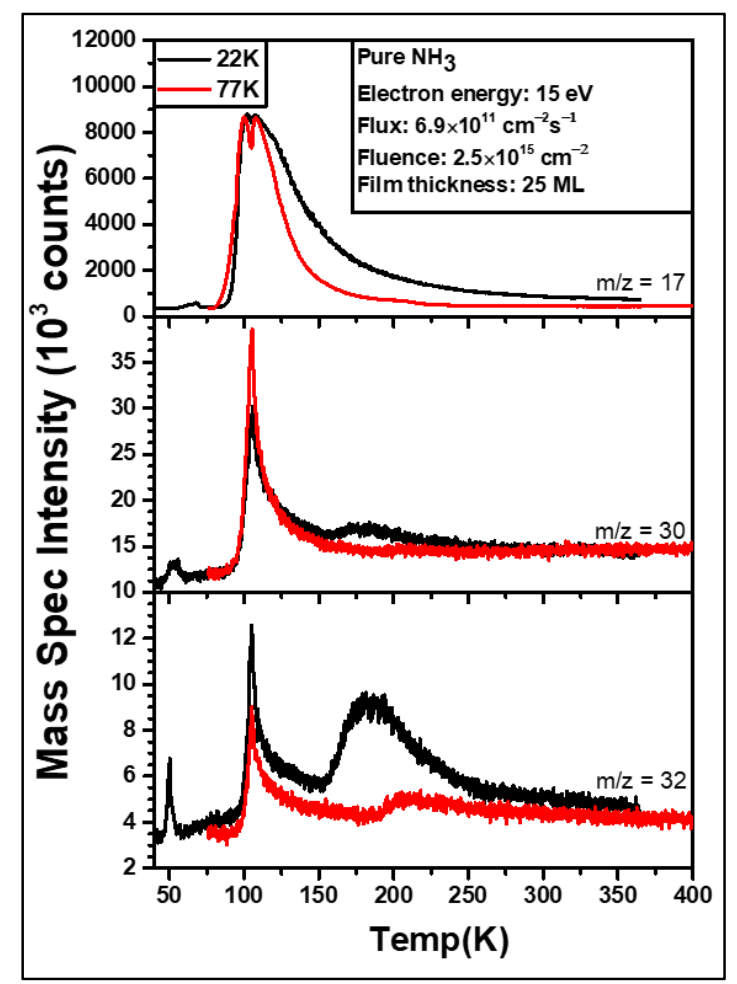

Figure 8

Post-irradiation TPD data following the irradiation of 25 monolayer $\mathrm{NH}_{3}$ film with $15 \mathrm{eV}$ electrons at two different ice temperatures, $22 \mathrm{~K}$ and $77 \mathrm{~K}$.

Results of separate photochemistry studies of condensed ammonia support our hypothesis that $\mathrm{NH}_{2}$ radicals desorb at an ice temperature of $90 \mathrm{~K} .{ }^{13}$ Hydrazine synthesis is observed at an ice temperature of $90 \mathrm{~K}$ following irradiation of ammonia ices with $<7.4 \mathrm{eV}$ photons which we estimate have a large mean free path of 0.2 microns, allowing for the synthesis of $\mathrm{NH}_{2}$ radicals significantly below the ammonia ice surface, therefore reducing radical desorption.

\subsection{Radiation yield as a function of electron flux}

The effect of electron flux (dose rate) on the ammonia radiolysis product yield was investigated by conducting post-irradiation TPD experiments while keeping constant the electron energy (1000 eV), film thickness (500 ML), and ice temperature (90 K); the electron current and irradiation time were varied, but the total electron fluence (dose) was kept constant $\left(8.2 \times 10^{14}\right.$ 
electrons $\mathrm{cm}^{-2}$ ). Results of these experiments appear to show a dose-rate effect for the production of both hydrazine and diazene (Figure 9). The red curves are simply used to guide the reader's eye and have no physical/mathematical basis. Below an incident current of $\sim 2.5 \mu \mathrm{A}$, the yields of both hydrazine and diazene more or less increase with increasing incident flux (current) at constant fluence (total incident charge). This dependence on flux (dose rate) is surprising given that electrons are categorized as low linear energy transfer (LET) radiation for which the radiolysis yield depends only on radiation dose (fluence) and not on dose rate (flux). ${ }^{\mathrm{d}} \mathrm{We}$ attribute this unexpected result obtained at an ice temperature of $90 \mathrm{~K}$ to $\mathrm{NH}_{2}$ and $\mathrm{NH}$ radical desorption which competes with the dimerization that yield hydrazine and diazene, respectively. At higher electron flux, radicals are more likely to be produced closer to each other, increasing the probability for dimerization while the probability for radical desorption remains unchanged. The yield vs. dose-rate curves eventually plateau likely because at higher fluxes the likelihood increases that the products are destroyed by subsequently arriving electrons.

\footnotetext{
${ }^{\mathrm{d}}$ In contrast, high LET radiation such as $\alpha$ particles produce closely spaced ionizations which lead to a dose-rate effect.
} 


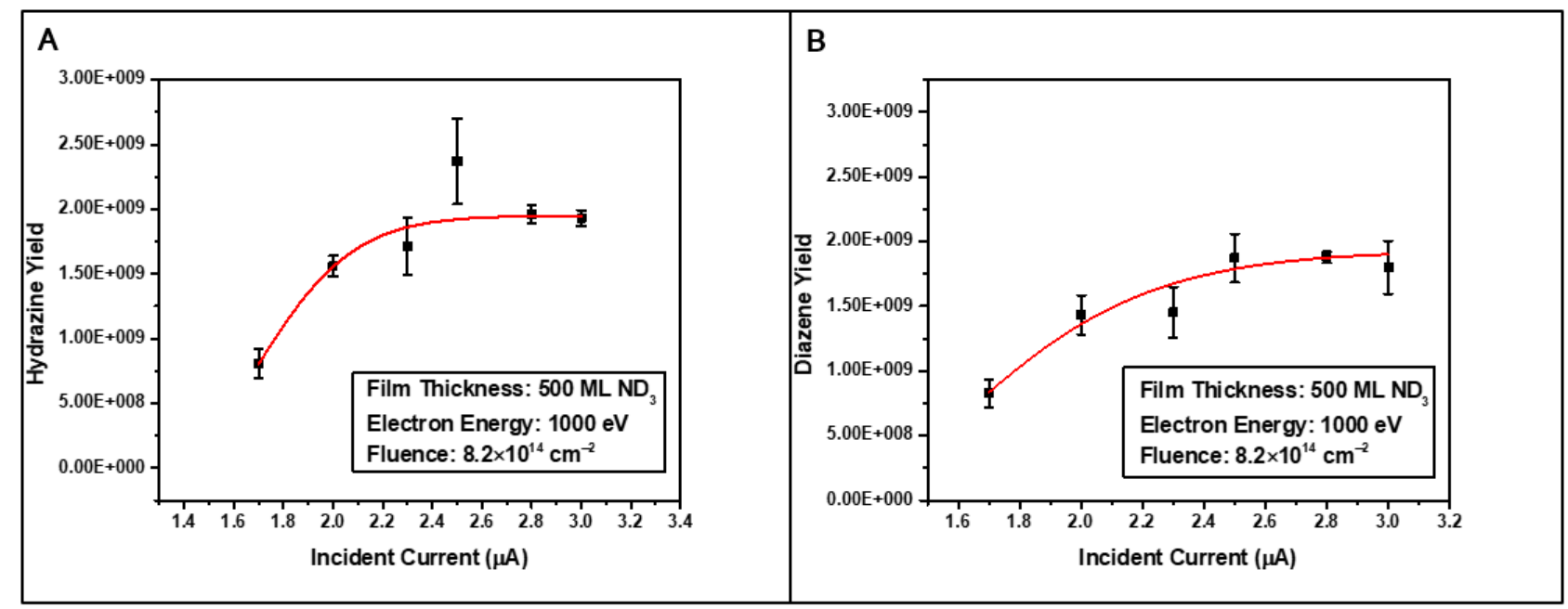

\section{Figure 9}

$\mathrm{ND}_{3}$ (500 monolayer) films were irradiated with $1000 \mathrm{eV}$ electrons. Flux and irradiation times were varied during these experiments to ensure a constant fluence (dose). The yields of hydrazine (A) and the yields of diazene (B) are plotted as a function of flux (dose rate) at constant electron fluence (dose). Data was fit to a logarithmic function for visual guidance (red). The error bars represent standard deviations of the mean.

\subsection{Astrochemical Implications}

While gas-phase reactions and surface reactions on bare carbonaceous or silicaceous dust grains contribute to cosmic chemistry, energetic processing of cosmic ices via photochemistry and radiation chemistry is thought to be the dominant mechanism for the extraterrestrial synthesis of prebiotic molecules. ${ }^{54}$ Discerning the role of photochemistry vs. radiation chemistry in astrochemistry requires a molecular-level mechanistic understanding these two processes. While the results discussed above provide insight into the radiolytic mechanisms for production of hydrazine $\left(\mathrm{N}_{2} \mathrm{H}_{4}\right)$ and diazene $\left(\mathrm{N}_{2} \mathrm{H}_{2}\right)$ from condensed ammonia, our preliminary TPD results (Supporting Information, Figure D: post-irradiation $\mathrm{TPD}$ of $\mathrm{ND}_{3}$ showing) also show evidence for the production of triazane $\left(\mathrm{N}_{3} \mathrm{H}_{5}\right)$ and cyclotriazane/triazene $\left(\mathrm{N}_{3} \mathrm{H}_{3}\right)$ following high-energy $(1000 \mathrm{eV})$ electron irradiation of condensed ammonia, consistent with previous studies..$^{30-31}$ The same reaction products are also observed following energetic processing of condensed ammonia by non-ionizing radiation consisting of $<7.4 \mathrm{eV}$ photons. ${ }^{13}$ This similarity, surprising given the 
myriad differences between photon- and electron- induced processes,${ }^{13}$ suggests that electronic excitation followed by dissociation to form radicals is the dominant mechanism for the photochemistry and radiation chemistry of condensed ammonia. The results presented in this publication are consistent with dimerization of radicals to form N-2 species following radiolysis of condensed ammonia. Studies such as these are necessary for incorporation into astrochemical models which since 2018 have begun to take into account condensed phase radiolysis induced by cosmic rays, allowing gas-phase chemistry, diffusive grain-surface chemistry, and ice-mantle photolysis and radiolysis to be simulated in tandem using rate equation-based modeling methods..$^{55-56}$

\section{Conclusion}

We provide a comprehensive report on condensed ammonia radiolysis as a function of (a) initial electron characteristics (energy, flux, and fluence) and (b) film features (thickness and temperature). Results of post-irradiation TPD experiments demonstrate the electron-induced production of hydrazine $\left(\mathrm{N}_{2} \mathrm{H}_{4}\right)$ and diazene $\left(\mathrm{N}_{2} \mathrm{H}_{2}\right)$ from ammonia condensed on both $\mathrm{Mo}(110)$ and $\mathrm{Ta}(110)$. Identification of these two radiolysis products was verified by conducting experiments with isotopologues of $\mathrm{NH}_{3}$. Based on theoretical considerations, we argue that the electron-induced formation of $\mathrm{NH}$ radicals from condensed ammonia is not subject to spin conservation rules. From yield versus (1) irradiation time and (2) film thickness results, we suggest that both hydrazine and diazene are formed via two-step reaction mechanisms involving bimolecular steps for the dimerization of $\mathrm{NH}_{2}$ and $\mathrm{NH}$ radicals, respectively. The enhanced desorption of these radical intermediates at an ice temperature of $90 \mathrm{~K}$ during electron irradiation contributes to (1) the surprising absence of detectable radiolysis products at incident electron energies below $10 \mathrm{eV}$ and (2) the unanticipated dependence of the radiolysis yield on electron 
dose rate at $90 \mathrm{~K}$. At an ice temperature of $22 \mathrm{~K}$, however, hydrazine formation occurs at incident electron energies as low as $7 \mathrm{eV}$, consistent with the widely-accepted hypothesis that low-energy secondary electrons mediate high-energy radiolysis in condensed matter.

\section{Acknowledgments}

This work was supported by grants from the National Science Foundation (NSF grant number CHE-1465161), Wellesley College (Faculty awards and Brachman Hoffman small grants), and the Natural Sciences and Engineering Research Council of Canada (NSERC).

\section{Supporting Information}

1. Representative temperature-programmed desorption experiment of $\mathrm{ND}_{3}$ performed in the absence of prior irradiation

2. Post-irradiation temperature-programmed desorption experiment of deuterated ammonia $\left(\mathrm{ND}_{3}\right)$

3. Post-irradiation temperature-programmed desorption experiment of ${ }^{15} \mathrm{NH}_{3}$.

4. Evidence for the production of triazane $\left(\mathrm{N}_{3} \mathrm{H}_{5}\right)$ and cyclotriazane/triazene $\left(\mathrm{N}_{3} \mathrm{H}_{3}\right)$ following high-energy $(1000 \mathrm{eV})$ electron irradiation of condensed ammonia.

\section{$\underline{\text { References }}$}

1. Bolton, S. J.; Adriani, A.; Adumitroaie, V.; Allison, M.; Anderson, J.; Atreya, S.; Bloxham, J.; Brown, S.; Connerney, J. E. P.; DeJong, E.; Folkner, W.; Gautier, D.; Grassi, D.; Gulkis, S.; Guillot, T.; Hansen, C.; Hubbard, W. B.; less, L.; Ingersoll, A.; Janssen, M.; Jorgensen, J.; Kaspi, Y.; Levin, S. M.; Li, C.; Lunine, J.; Miguel, Y.; Mura, A.; Orton, G.; Owen, T.; Ravine, M.; Smith, E.; Steffes, P.; Stone, E.; Stevenson, D.; Thorne, R.; Waite, J.; Durante, D.; Ebert, R. W.; Greathouse, T. K.; Hue, V.; Parisi, M.; Szalay, J. R.; Wilson, R., Jupiter's interior and deep atmosphere: The initial pole-to-pole passes with the Juno spacecraft. Science 2017, 356 (6340), 821-825.

2. Atreya, S. K.; Mahaffy, P. R.; Niemann, H. B.; Wong, M. H.; Owen, T. C., Composition and origin of the atmosphere of Jupiter - an update, and implications for the extrasolar giant planets. Planet Space Sci. 2003, 51 (2), 105-112.

3. Hofstadter, M. D.; Muhleman, D. O., Latitudinal Variations of Ammonia in the Atmosphere of Uranus - an Analysis of Microwave Observations. Icarus 1989, 81 (2), 396-412. 
4. Lindal, G. F., The Atmosphere of Neptune - an Analysis of Radio Occulation Data Acquired with Voyager-2. Astron. J. 1992, 103 (3), 967-982.

5. Bauer, J. M.; Roush, T. L.; Geballe, T. R.; Meech, K. J.; Owen, T. C.; Vacca, W. D.; Rayner, J. T.; Jim, K. T. C., The near infrared spectrum of Miranda - Evidence of crystalline water ice. Icarus 2002, 158 (1), 178-190.

6. Wyckoff, S.; Tegler, S. C.; Engel, L., Ammonia Abundances in 4 Comets. Astrophysical Journal 1991, 368 (1), 279-286.

7. Greenberg, J. M.; Vandebult, C.; Allamandola, L. J., Ices in Space. Journal of Physical Chemistry 1983, 87 (21), 4243-4260.

8. Vandishoeck, E. F.; Jansen, D. J.; Schilke, P.; Phillips, T. G., DETECTION OF THE INTERSTELLAR NH2 RADICAL. Astrophysical Journal 1993, 416 (2), L83-L86.

9. Nourry, S.; Krim, L., Formation of simple nitrogen hydrides $\mathrm{NH}$ and $\mathrm{NH} 2$ at cryogenic temperatures through $\mathrm{N}+\mathrm{NH} 3->\mathrm{NH}+\mathrm{NH} 2$ reaction: dark cloud chemistry of nitrogen. Physical Chemistry Chemical Physics 2016, 18 (27), 18493-18499.

10. Altwegg, K.; Balsiger, H.; Bar-Nun, A.; Berthelier, J. J.; Bieler, A.; Bochsler, P.; Briois, C.; Calmonte, U.; Combi, M. R.; Cottin, H.; De Keyser, J.; Dhooghe, F.; Fiethe, B.; Fuselier, S. A.; Gasc, S.; Gombosi, T. I.; Hansen, K. C.; Haessig, M.; Jackel, A.; Kopp, E.; Korth, A.; Le Roy, L.; Mall, U.; Marty, B.; Mousis, O.; Owen, T.; Reme, H.; Rubin, M.; Semon, T.; Tzou, C. Y.; Waite, J. H.; Wurz, P., Prebiotic chemicals-amino acid and phosphorus-in the coma of comet 67P/Churyumov-Gerasimenko. Science Advances 2016, 2 (5), e1600285.

11. Zaleski, D. P.; Seifert, N. A.; Steber, A. L.; Muckle, M. T.; Loomis, R. A.; Corby, J. F.; Martinez, O.; Crabtree, K. N.; Jewell, P. R.; Hollis, J. M.; Lovas, F. J.; Vasquez, D.; Nyiramahirwe, J.; Sciortino, N.; Johnson, K.; McCarthy, M. C.; Remijan, A. J.; Pate, B. H., Detection of E-Cyanomethanimine toward Sagittarius B2(N) in the Green Bank Telescope Primos Survey. Astrophys J Lett 2013, 765 (1), L10.

12. Smith, I. W. M.; Talbi, D.; Herbst, E., The production of HCN dimer and more complex oligomers in dense interstellar clouds. Astronomy \& Astrophysics 2001, 369 (2), 611-615.

13. Mullikin, E.; van Mulbregt, P.; Perea, J.; Kasule, M.; Huang, J.; Buffo, C.; Campbell, J.; Gates, L.; Cumberbatch, H. M.; Peeler, Z.; Schneider, H.; Lukens, J.; Bao, S. T.; Tano-Menka, R.; Baniya, S.; Cui, K.; Thompson, M.; Hay, A.; Widdup, L.; Caldwell-Overdier, A.; Huang, J.; Boyer, M. C.; Rajappan, M.; Echebiri, G.; Arumainayagam, C. R., Condensed-Phase Photochemistry in the Absence of Radiation Chemistry. ACS Earth and Space Chemistry 2018, 2 (9), 863-868.

14. Bossa, J. B.; Borget, F.; Duvernay, F.; Theule, P.; Chiavassa, T., Formation of neutral methylcarbamic acid $(\mathrm{CH} 3 \mathrm{NHCOOH})$ and methylammonium methylcarbamate $\mathrm{CH} 3 \mathrm{NH} 3+\mathrm{CH} 3 \mathrm{NHCO} 2-$ at low temperature. Journal of Physical Chemistry A 2008, 112 (23), 5113-5120.

15. Öberg, K. I., Photochemistry and Astrochemistry: Photochemical Pathways to Interstellar Complex Organic Molecules. Chem. Rev. 2016, 116 (17), 9631-9663.

16. Bass, A. D.; Sanche, L., Reactions induced by low energy electrons in cryogenic films (Review). Low Temp Phys+ 2003, 29 (3), 202-214.

17. Arumainayagam, C. R.; Lee, H.-L.; Nelson, R. B.; Haines, D. R.; Gunawardane, R. P., Low-energy electron-induced reactions in condensed matter. Surface Science Reports 2010, 65 (1), 1-44.

18. Bohler, E.; Warneke, J.; Swiderek, P., Control of chemical reactions and synthesis by low-energy electrons. Chemical Society Reviews 2013, 42 (24), 9219-9231.

19. Boyer, M. C.; Rivas, N.; Tran, A. A.; Verish, C. A.; Arumainayagam, C. R., The role of low-energy $1<=20 \mathrm{eV}$ ) electrons in astrochemistry. Surface Science 2016, 652, 26-32.

20. Esmaili, S.; Bass, A. D.; Cloutier, P.; Sanche, L.; Huels, M. A., Glycine formation in CO2: $\mathrm{CH} 4: \mathrm{NH} 3$ ices induced by 0-70 eV electrons. Journal of Chemical Physics 2018, 148 (16), 8.

21. Andersen, W. H.; Zwolinski, B. J.; Parlin, R. B., HYDRAZINE FROM AMMONIA. Industrial and Engineering Chemistry 1959, 51 (4), 527-530. 
22. Melton, C. E., STUDY BY MASS SPECTROMETRY OF DECOMPOSITION OF AMMONIA BY IONIZING RADIATION IN A WIDE-RANGE RADIOLYSIS SOURCE. Journal of Chemical Physics 1966, 45 (12), 4414-\&.

23. B, P. M., Report says social sciences can help avoid policy goofs. Science 1969, 165 (3893), 574.

24. Bordalo, V.; da Silveira, E. F.; Lv, X. Y.; Domaracka, A.; Rothard, H.; Duarte, E. S.; Boduch, P., Chemical Processing of Pure Ammonia and Ammonia-Water Ices Induced by Heavy lons. Astrophysical Journal 2013, 774 (2), 105.

25. Moore, M. H.; Ferrante, R. F.; Hudson, R. L.; Stone, J. N., Ammonia-water ice laboratory studies relevant to outer Solar System surfaces. Icarus 2007, 190 (1), 260-273.

26. Lv, X. Y.; Boduch, P.; Ding, J. J.; Domaracka, A.; Langlinay, T.; Palumbo, M. E.; Rothard, H.; Strazzulla, G., Thermal and energetic processing of ammonia and carbon dioxide bearing solid mixtures. Physical Chemistry Chemical Physics 2014, 16 (8), 3433-3441.

27. Parent, P.; Bournel, F.; Lasne, J.; Lacombe, S.; Strazzulla, G.; Gardonio, S.; Lizzit, S.; Kappler, J. P.; Joly, L.; Laffon, C.; Carniato, S., The irradiation of ammonia ice studied by near edge x-ray absorption spectroscopy. Journal of Chemical Physics 2009, 131 (15), 154308.

28. Zheng, W. J.; Jewitt, D.; Osamura, Y.; Kaiser, R. I., Formation of nitrogen and hydrogen-bearing molecules in solid ammonia and implications for solar system and interstellar ices. Astrophysical Journal 2008, 674 (2), 1242-1250.

29. Barberio, M.; Barone, P.; Vasta, R.; Manico, G.; Xu, F., Formation of molecular nitrogen and diazene by electron irradiation of solid ammonia. Thin Solid Films 2012, 520 (16), 5479-5481.

30. Förstel, M.; Maksyutenko, P.; Jones, B. M.; Sun, B. J.; Chen, S. H.; Chang, A.; Kaiser, R. I., Detection of the Elusive Triazane Molecule (N3H5) in the Gas Phase. ChemPhysChem 2015, 16 (15), 3139-3142.

31. Förstel, M. T., Y. A.; Maksunyutenko, P.; Mebel, A. M.; Sander, W.; Kaiser, R. I., On the Formation of N3H3 Isomers in Irradiated Ammonia Bearing Ices: Triazene (H2NNNH) or Triimide (HNHNNH). Chem. Phys. Chem. 2016, 17, 2726-2735.

32. Harris, T. D.; Lee, D. H.; Blumberg, M. Q.; Arumainayagam, C. R., Electron-Induced Reactions in Methanol Ultrathin Films Studied by Temperature-Programmed Desorption - a Useful Method to Study Radiation-Chemistry. Journal of Physical Chemistry 1995, 99 (23), 9530-9535.

33. Fillion, J. H.; Fayolle, E. C.; Michaut, X.; Doronin, M.; Philippe, L.; Rakovsky, J.; Romanzin, C.; Champion, N.; Oberg, K. I.; Linnartz, H.; Bertin, M., Wavelength resolved UV photodesorption and photochemistry of CO2 ice. Faraday Discuss 2014, 168, 533-552.

34. Fayolle, E. C.; Balfe, J.; Loomis, R.; Bergner, J.; Graninger, D.; Rajappan, M.; Oberg, K. I., N-2 AND CO DESORPTION ENERGIES FROM WATER ICE. Astrophys J Lett 2016, 816 (2), 6.

35. du Penhoat, M. A. H.; Huels, M. A.; Cloutier, P.; Jay-Gerin, J. P.; Sanche, L., Anion fragment formation in 5-halouracil films induced by 1-20 eV electron impact. Journal of Physical Chemistry $B$ 2004, 108 (44), 17251-17260.

36. Esmaili, S.; Bass, A. D.; Cloutier, P.; Sanche, L.; Huels, M. A., Synthesis of complex organic molecules in simulated methane rich astrophysical ices. Journal of Chemical Physics 2017, 147 (22), 224704.

37. Sanche, L., Transmission of 0-15 eV monoenergetic electrons through thin-film molecular solids. J. Chem. Phys. 1979, 71 (12), 4860-82.

38. Linstrom, P. J.; Mallard, W. G., The NIST Chemistry WebBook: A chemical data resource on the internet. J. Chem. Eng. Data 2001, 46 (5), 1059-1063.

39. Rawat, P.; Prabhudesai, V. S.; Rahman, M. A.; Ram, N. B.; Krishnakumar, E., Absolute cross sections for dissociative electron attachment to $\mathrm{NH} 3$ and $\mathrm{CH} 4$. International Journal of Mass Spectrometry 2008, 277 (1-3), 96-102.

40. Sharp, T. E.; Dowell, J. T., DISSOCIATIVE ATTACHMENT OF ELECTRONS IN AMMONIA AND AMMONIA-D3. Journal of Chemical Physics 1969, 50 (7), 3024-\&. 
41. Tronc, M.; Azria, R.; LeCoat, Y.; Illenberger, E., Threefold differential electron-stimulated desorption yields of D- anions from multilayer films of D2O and ND3 condensed on platinum. Journal of Physical Chemistry 1996, 100 (35), 14745-14750.

42. Bater, C.; Campbell, J. H.; Craig, J. H., H- ESD observed from beta-state NH3 adsorbed on Pt(111). Thin Solid Films 1999, 340 (1-2), 7-10.

43. Leach, S.; Jochims, H. W.; Baumgartel, H., VUV Photodissociation of ammonia: a dispersed fluorescence excitation spectral study. Physical Chemistry Chemical Physics 2005, 7 (5), 900-911.

44. Souda, R., Radiolysis of $\mathrm{NH} 3, \mathrm{C} 2 \mathrm{H} 6, \mathrm{C} 2 \mathrm{H} 4$, and $\mathrm{CF} 6$ molecules in physisorbed ultrathin films studied by electron-stimulated desorption. Chemical Physics Letters 2003, 382 (3-4), 387-392.

45. Yu, K. Y.; McMenamin, J. C.; Spicer, W. E., UPS Measurements of Molecular Energy-level of Condensed Gases. Surface Science 1975, 50 (1), 149-156.

46. Kaplan, I. G.; Miterev, A. M., Interaction of charged particles with molecular medium and track effects in radiation chemistry. Adv. Chem. Phys. 1987, 68, 255-386.

47. Cvejanovic, S.; Jureta, J.; Minic, M.; Cvejanovic, D., TRIPLET-STATES OF AMMONIA EXCITED BY LOW-ENERGY ELECTRONS. Journal of Physics B-Atomic Molecular and Optical Physics 1992, 25 (20), 4337-4349.

48. Warneke, J.; Wang, Z. Y.; Swiderek, P.; Bredehoft, J. H., Electron-Induced Hydration of an Alkene: Alternative Reaction Pathways. Angewandte Chemie-International Edition 2015, 54 (14), 4397-4400.

49. Thompson, A.; Attwood, D.; Gullikson, E.; Howells, M.; Kim, K.-J.; Kirz, K.; Kortright, J., X-ray data booklet. Third ed.; Lawrence Berkeley National Laboratory: Berkeley, CA, , 2009.

50. Plante, I.; Cucinotta, F. A., Cross sections for the interactions of $1 \mathrm{eV}-100 \mathrm{MeV}$ electrons in liquid water and application to Monte-Carlo simulation of HZE radiation tracks. New J. Phys. 2009, 11, 24.

51. Boehler, E.; Bredehoeft, J. H.; Swiderek, P., Low-Energy Electron-Induced Hydroamination Reactions between Different Amines and Olefins. Journal of Physical Chemistry C 2014, 118 (13), $6922-$ 6933.

52. Cuppen; Oba; Congiu; Dulieu; Kaiser; Price; Meuwly; Hama; Minissale; Ioppolo; McCoustra; Zins; Garrod; Watanabe; Herbst; Heard; Schram; Zacharias; Vidali; McGregor; Linnartz; Lamberts; Rawlings; Arumainayagam; Woods; Kamp; Mason; Meijer; Hornekraer; Jones; Mate; Rimola; Fukushima; Ellinger; Drozdovskaya; Jager; Fillion; Heays, General Discussion. Faraday Discuss 2014, 168, 571-615.

53. Gumus, H.; Bentabet, A., CSDA range, stopping power and mean penetration depth energy relationships in some hydrocarbons and biologic materials for $10 \mathrm{eV}$ to $100 \mathrm{MeV}$ with the modified Rohrlich-Carlson model. Applied Physics a-Materials Science \& Processing 2017, 123 (5), 9.

54. Arumainayagam, C. R.; Garrod, R. T.; Boyer, M. C.; Hay, A. K.; Bao, S. T.; Campbell, J. S.; Wang, J.; Nowak, C. M.; Arumainayagam, M. R.; Hodge, P. J., Extraterrestrial Prebiotic Molecules: Photochemistry vs. Radiation Chemistry of Interstellar Ices. Chemical Society Reviews 2019, DOI: 10.1039/c7cs00443e.

55. Shingledecker, C. N.; Herbst, E., A general method for the inclusion of radiation chemistry in astrochemical models. Physical Chemistry Chemical Physics 2018, 20 (8), 5359-5367.

56. Shingledecker, C. N.; Tennis, J.; Le Gal, R.; Herbst, E., On Cosmic-Ray-driven Grain Chemistry in Cold Core Models. Astrophysical Journal 2018, 861 (1), 15. 


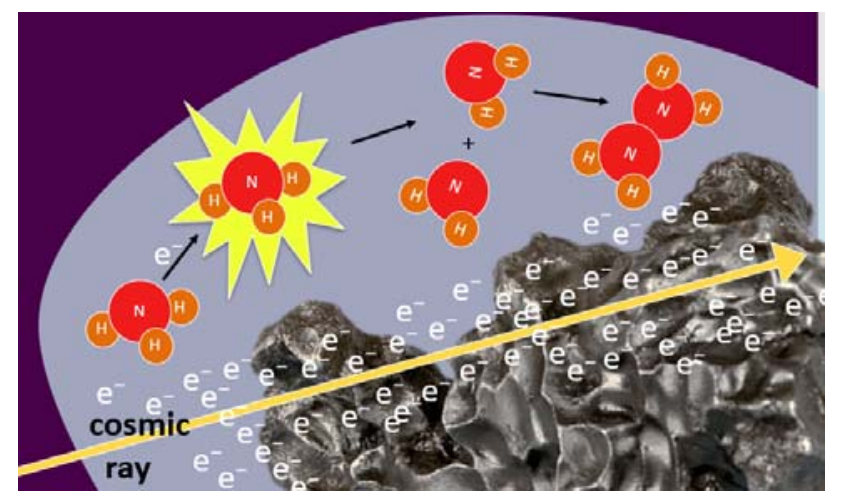

